\title{
Milliliter per Kilogram per Second
}

National Cancer Institute

\section{Source}

National Cancer Institute. Milliliter per Kilogram per Second. NCI Thesaurus. Code C85715.

Milliliters per kilogram per second. 